\title{
El prejuicio y la cuestión crítica: una tensión fundamental en Verdad y método
}

\section{Prejudice and question of critique: an essential tension in Truth and Method}

Ramón Bárcenas Deanda

Universidad de Guanajuato

\begin{abstract}
Resumen
Gadamer afirma contra la lectura moderna del prejuicio que éste no es mera fuente de error sino un modo de experimentar la verdad. El prejuicio es rehabilitado por la hermenéutica gadameriana al mostrar su carácter condicionante de la comprensión. A pesar de esta reivindicación, lo cierto es que el prejuicio puede conducirnos tanto a la verdad como al error. Por esta razón, es necesario diferenciar los presupuestos que nos llevan a la comprensión de aquellos que nos conducen al malentendido. A esta exigencia Gadamer la caracteriza como la "verdadera cuestión crítica de la hermenéutica”. En este texto se propone la existencia de una tensión fundamental entre la rehabilitación ontológica-hermenéutica del prejuicio y la demanda metodológica de distinguir los presupuestos legítimos de los ilegítimos.
\end{abstract}

Palabras claves: ontología, hermenéutica, prejuicio, cuestión crítica, epistemología. 


\begin{abstract}
Gadamer holds against the modern reading of prejudice, which conceives it as a mere source of error, that it is above all a form of experiencing truth. Hermeneutics shows that prejudice conditions understanding. Despite this defense, it is the case that assumptions can equally lead to understanding or misunderstanding. For this reason, Gadamer argues that it is necessary to distinguish between productive and unproductive prejudices. This methodological task is known as "question of critique in hermeneutics". In this article it is argued that these two different forms of understanding prejudice bring about an essential tension in Gadamer's hermeneutics.
\end{abstract}

Keywords: Ontology, Hermeneutics, Prejudice, Question of critique, Epistemology.

Ausencia de perspectiva, si la expresión ha de significar algo, no es otra cosa que la explícita apropiación del punto de vista.

HeIDEgGer

\title{
I. La rehabilitación hermenéutica del prejuicio
}

En n su obra principal, Verdady método, Gadamer subraya que los filósofos modernos asumieron una noción negativa del prejuicio, pues lo concibieron como una fuente de error. De acuerdo con esta concepción, los prejuicios se clasifican en dos grupos generales: los de precipitación y los de autoridad. El primer tipo consiste en juzgar como verdadera una pieza de información sin haberla sometido a un examen riguroso. Por ejemplo, cuando asentimos apresuradamente a los datos sensoriales, a pesar de su carácter fa- 
lible. En la "Meditación Segunda" Descartes expone dicha falibilidad mediante el caso de la cera expuesta al fuego, la cual cambia de forma, aroma, color, etc. Los atributos sensibles son cualidades secundarias que no posibilitan un conocimiento sustancial de las cosas. La distinción entre cualidades primarias y secundarias se corresponde con la diferencia entre los planos subjetivo y objetivo. Mientras que las cualidades secundarias (color, aroma, textura, etc.) remiten al modo en que los objetos afectan nuestra sensibilidad, las cualidades primarias (extensión, movimiento, aceleración, etc.) son elementos inherentes a las cosas mismas.

El segundo tipo de prejuicios se relaciona con la obediencia acrítica al decir de las figuras de autoridad. La actitud de sumisión a la palabra de preceptores y de la tradición acontece en detrimento de la autonomía de pensamiento, lo cual ha sido caracterizado por Kant como la autoculpable incapacidad (1994: 25). Es importante resaltar que ésta no remite a algún tipo de deficiencia en la facultad de juzgar como tal. Ya Descartes había señalado en su Discurso que el buen sentido es "naturalmente igual en todos los hombres" (2006: 39). La culpable incapacidad remite más bien a un comportamiento humano, consistente en la cobardía para hacer uso de la propia razón. La emancipación de los tutores requiere de una toma de decisión que conlleva un notable esfuerzo. Kant nos exhorta a ello en los siguientes términos: "¡Sapere aude! ¡Ten el valor de servirte de tu propia razón!” (1994: 25). Éste es un llamado a liberarse de toda forma de autoridad que pretenda usurpar el lugar de la razón. De esta exhortación se sigue una cierta oposición entre la tradición, como figura de autoridad, y la razón. Esta contraposición constituye una de las tesis centrales del pensamiento moderno que el filósofo de Heidelberg buscará desarticular para rehabilitar la tradición como fuente de verdad.

Gadamer considera que la valoración ilustrada del prejuicio constituye ella misma un prejuicio contra todo presupuesto; lo 
cual da lugar a una desafortunada depreciación de la tradición. Para rehabilitar la tradición como posible experiencia de verdad es necesario desarticular el prejuicio ilustrado en varios frentes. En primer lugar, elabora un examen propio de su formación de filólogo y argumenta que no existe una implicación necesaria entre prejuicio y juicio falso. El vocablo "prejuicio" significa juicio previo; de modo que en el proceso jurisprudencial quiere decir pre-decisión. Es una toma de postura previa a una constatación concluyente. En este sentido, y sólo en éste, prejuicio sería equivalente a un planteamiento conjetural. Y así como una hipótesis no es una noción falsa, sino solamente alude a una posibilidad cuyo valor de verdad requiere ser constatado, así también el prejuicio es sólo una suposición y no una concepción errónea. "En sí mismo "prejuicio» quiere decir un juicio que se forma antes de la convalidación definitiva de todos los momentos que son objetivamente determinantes" (Gadamer, 2001: 337). Lo que Gadamer quiere resaltar es que también puede haber prejuicios productivos que conduzcan a la correcta comprensión. Y si esto es posible, entonces hay buenas razones para reconsiderar la perspectiva moderna de valorar la tradición. En palabras de Gadamer: "Si existen también prejuicios justificados y que pueden ser productivos para el conocimiento, entonces el problema de la autoridad se nos vuelve a plantear de nuevo" (2001: 346).

En segundo lugar, Gadamer busca mostrar que no existe una oposición excluyente entre autoridad y razón. En principio reconoce que la crítica ilustrada a la autoridad no es del todo arbitraria, particularmente en aquellos casos en que la fe ciega en los tutores usurpa el lugar de la razón. Cuando esto sucede, la crítica a las figuras de autoridad está justificada. Esto, sin embargo, no anula la posibilidad de que tanto preceptores como la tradición puedan "ser también una fuente de verdad, cosa que la Ilustración ignoró sistemáticamente en su repulsa generalizada contra toda autori- 
dad" (2001: 346). Tomemos el caso de los expertos o especialistas, los cuales conocen sobre ciertos temas más que los demás. La autoridad de estas personas, lejos de ser una mera imposición, reposa en el consentimiento de los otros. Se concede autoridad a alguien cuando se re-conoce que sabe más del tema que nosotros.

[...] la autoridad de las personas no tiene su fundamento último en un acto de sumisión y de abdicación de la razón, sino en un acto de reconocimiento y de conocimiento: se reconoce que el otro está por encima de uno en juicio y perspectiva y que en consecuencia su juicio es preferente" (Gadamer, 2001: 347).

Por lo tanto, atender a la voz de los autores no reside en un mero acto de subordinación acrítica, de modo que la oposición excluyente entre razón y autoridad no es del todo correcta. Por un lado, porque la autoridad también puede ser fuente de saber, tal es el caso de los autores y expertos; por otro, porque la validez de la autoridad tiene su fundamento en un acto de la razón, a saber, en el reconocimiento de que el otro tiene un mejor punto de vista que el propio.

En tercer lugar, la tradición, como figura de autoridad, remite a aquellas prácticas, ideas, conocimientos y realidades que se han consagrado y transmitido a través del transcurso del tiempo. Por esta razón, la tradición, en cuanto modo de conservación, siempre se encuentra presente en todo acontecer histórico. Gadamer señala que en toda revolución, incluso en las más drásticas, siempre hay más permanencia de lo que usualmente se quiere admitir. Pero esta conservación no debe ser vista como el resultado de una mera preferencia por lo antiguo, como podría ser el caso de la predilección romántica por el pasado. La autoridad de la tradición también encuentra su justificación en un acto de la libertad y de la historia. Incluso la costumbre más venerable no se sostiene simplemente por la pura inercia de las cosas sino que "necesita ser afirmada, 
asumida y cultivada" (Gadamer: 2001: 349). En este sentido, una tradición como la filosófica se constituye como tal gracias al constante y renovado trato con los problemas, las preguntas y las ideas que la definen. A lo que aquí se apela es a la racionalidad inherente en la preservación y transmisión de saberes, prácticas e ideas a través del tiempo.

El ejemplo predilecto del filósofo de Heidelberg, respecto a la autoridad de la tradición, lo encuentra en la figura de lo clásico; caso que toma de su propia área de formación: la filología. Contra una interpretación excesivamente historicista de lo clásico, que ve en éste solamente un concepto de época referente a un determinado período histórico, argumenta que lo clásico nunca pierde su carácter canónico, sino que como tal conserva un contenido de valor cuya vigencia sigue siendo actual. Esto, por supuesto, no implica que devenga en un valor suprahistórico, sino que habrá que comprenderlo como una categoría histórica. Lo clásico no es un concepto que se emplee para clasificar un determinado período del pasado. Por el contrario, remite a un modo de ser histórico, (la permanencia y la transmisión), al cual se encuentra vinculada y sometida la propia conciencia del sujeto. Como seńala el propio Gadamer, lo clásico no remite a "una cualidad que se atribuya a determinados fenómenos históricos, sino [a] un modo característico del mismo ser histórico, la realización de una conservación que, en una confirmación constantemente renovada, hace posible la existencia de algo que sea verdad" (2001: 356).

Con esta defensa de la autoridad en varios frentes se busca lograr lo siguiente. Por un lado, rehabilitar la tradición como posible experiencia de verdad, concretamente con el ejemplo de lo clásico. Por otro lado, al enfatizar que la autoridad también es fuente de saber, está argumentado contra la postura ilustrada que ve en la razón el criterio último de validez. Gadamer no se cansa de recordarnos que es una ilusión concebir la razón como dueña de sí misma 
y libre de todo condicionamiento. Los análisis heideggerianos de la existencia humana han revelado que el conocer está condicionado por la pre-comprensión. En El ser y el tiempo se muestra que es inherente al ser del Dasein (ser ahí) el que las cosas intramundanas se le presenten originariamente bajo la modalidad de algo como algo. En el trato ocupado con las cosas se comprende la mesa como tal, sin que esta comprensión tenga que hacerse explícita en una enunciación. Este "comprender como" es pre-teórico, pues mienta una capacidad originaria constitutiva del ser ahí. Este entender originario, llamado "como hermenéutico", es previo a toda consideración científica, de forma tal que se constituye en condición de posibilidad del "como apofántico". En esto consiste el significado de la estructura de la pre-comprensión, expuesta por Heidegger en el parágrafo 32: "la interpretación se ha decidido en cada caso ya, definitivamente o con reservas, por unos determinados conceptos; se funda en un 'concebir previo"' (2007: 168).

Gadamer asume la radicalidad ontológica de la tesis heideggeriana y la antepone a la valoración moderna del prejuicio. El prejuicio entonces no es un juicio sin fundamento, sino aquello que determina la propia actividad científica. En este sentido, todo proyecto interpretativo se encuentra siempre condicionado por presupuestos. Un investigador no se acerca a un texto con una actitud mental semejante a una tabula rasa, sino más bien como una tabula plena, llena de presupuestos. Con base en este reconocimiento, Gadamer se opone al principio que demanda comenzar una investigación libre de prejuicios. En esto sigue a Heidegger quien, en el texto de Ontología, consideró como un malentendido la exigencia de objetividad. No es posible alcanzar una base neutral sobre la cual construir el edificio del conocimiento, porque todo ver, incluyendo aquél que demanda hacerlo libre de ideas previas, "es un ver y tiene, en cuanto tal, su punto de vista" (2008: 107). 
Las consideraciones anteriores muestran que los prejuicios no son objetos que se puedan manipular a voluntad. Por el contrario, en cuanto elementos condicionantes de toda interpretación, definen el posicionamiento desde el cual tiene lugar un proyecto de investigación. En este sentido, configuran la situación hermenéutica y la situación es algo en lo que nos hallamos, no algo que se encuentra a nuestra total disposición. En palabras de Gadamer: "una situación hermenéutica está determinada por los prejuicios que nosotros aportamos. Estos forman así el horizonte de un presente, pues representan aquello más allá de lo cual ya no se alcanza a ver" (2001: 376). Los prejuicios, lejos de ser nociones erróneas, condicionan nuestro horizonte histórico. Aquí nos encontramos con el sentido esencial de la sentencia gadameriana de que nuestros prejuicios, más que nuestros juicios, configuran la realidad histórica de nuestro ser. Esto significa que no sólo los sucesos son históricos, sino que la propia conciencia del investigador está condicionada por la acción de la historia. La tesis de la historicidad de la conciencia tiene implicaciones fundamentales para la naturaleza del conocer: muestra que el conocedor y lo conocido no se ofrecen de manera óntica sino ontológica, lo cual quiere decir que "tienen el modo de ser de la historicidad" (Gadamer, 2000: 76). El hecho de que la misma conciencia científica esté sustentada por tradiciones históricas es lo que, en último término, posibilita hablar de historia.

Nos encontramos ante uno de los puntos clave del debate que Gadamer entabla con la modernidad. Para él no es posible la erradicación de todo prejuicio, y el consecuente establecimiento de verdades indubitables, porque la idea de una razón libre de toda determinación es una ilusión del pensamiento moderno. "Para nosotros la razón sólo existe como real e histórica, esto es, la razón no es dueña de sí misma sino que está siempre referida a lo dado en lo cual se ejerce" (2001: 343). Frente al ideal metódico y reflexi- 
vo, que persigue un punto de partida incondicionado y neutral, la hermenéutica gadameriana antepone la tesis de la historicidad de la propia conciencia científica. Se trata de la recuperación del sentido de pertenencia a las tradiciones históricas que nos preceden y sustentan. En palabras de Ricoeur: "Por provocante - por no decir provocador- que sea este alegato, tiene que ver con la reconquista de la dimensión histórica por sobre el momento reflexivo. La historia me precede y adelanta mi reflexión; yo pertenezco a la historia, antes de pertenecerme" (2002: 92). Con estas palabras se pone en entredicho la validez de uno de los supuestos fundamentales del racionalismo moderno: la idea de que la conciencia autorreflexiva se encuentra libre de todo condicionamiento.

\section{La cuestión crítica en la hermenéutica gadameriana}

A pesar de los esfuerzos hermenéuticos por reivindicar a la figura de autoridad como forma de verdad, lo cierto es que ella también puede llevar al malentendido. Los autores se equivocan y esto no sólo de manera inconsciente o por descuido, sino incluso deliberadamente, como cuando mienten por intereses personales o presionados por instancias de poder. Por otro lado, es importante reconocer, en contra de Gadamer, que las tradiciones conservan y transmiten verdades de la misma forma que errores o malentendidos. La tradición escolástica representaba para los modernos un obstáculo en la búsqueda de la verdad, no sólo porque ciertas ideas que promulgaba eran erróneas, sino sobre todo porque las autoridades eclesiásticas contaban con el poder efectivo de censurar y castigar toda voz disidente de sus propias creencias. En este sentido, la afirmación gadameriana de que también la crítica ilustrada a la autoridad tiene su razón de ser resulta desconsiderada. Los pensadores modernos no estaban simplemente justificados en disputar sobre un asunto con el que no estaban de acuerdo, sino 
que luchaban contra una instancia de poder que reprobaba la autonomía de pensamiento.

Además, el reconocimiento de la prioridad fundamental de los prejuicios no anula el problema de dilucidar su validez. A la tarea de determinar la legitimidad de los presupuestos Gadamer la llamó "la verdadera cuestión crítica de la hermenéutica"; la cual exige "distinguir los prejuicios verdaderos bajo los cuales comprendemos, de los prejuicios falsos que producen malentendidos" (2001: 369). Con esta exigencia se presenta una cuestión metodológica en el corazón mismo del pensamiento gadameriano, pues para determinar la validez de los presupuestos, éstos deben ser susceptibles de ser llevados al nivel de la conciencia. El asunto aquí es el modo en que tales pre-concepciones pueden ser traídas al plano de la conciencia. Existen varios pasajes en Verdad y método en los cuáles el autor plantea la revisión de los prejuicios en un tono epistemológico. Y son tales pasajes los que sugieren una tensión en su obra, pues la prioridad fundamental de los prejuicios impide que sean objeto de un examen crítico.

Gadamer señala que cuando nos acercamos a un texto siempre lo hacemos desde ciertas anticipaciones de sentido. Esto, por supuesto, no implica dar por sentado la legitimidad de tales expectativas. Por el contrario, un buen hermeneuta es aquél que procura no imponer sus nociones previas al texto, procurando atender al significado de la obra. "Toda interpretación correcta debe guardarse de la arbitrariedad de las ocurrencias y de la limitación de los hábitos mentales inadvertidos, y se fijará «en las cosas mismas» (que para el filólogo son textos significativos que tratan a su vez de cosas)" (Gadamer, 2002: 65). La observación de partir de las cosas mismas constituye una exigencia fenomenológica. En el parágrafo 32 de El ser y el tiempo, Heidegger subraya la posibilidad de alcanzar un saber fundamental, siempre y cuando la interpretación asuma que "su primera, constante y última función es evitar que 
las ocurrencias y los conceptos populares le impongan en ningún caso el 'tener', el 'ver' y el 'concebir' 'previos', para desenvolver éstos partiendo de las cosas mismas, de suerte que quede asegurado el tema científico" (2007: 171-172). Lo que aquí se demanda es evitar que las nociones arbitrarias determinen la comprensión, de forma tal que ésta logre desarrollarse partiendo de las cosas mismas. Jean Grondin señala que en alemán la palabra Sache (cosa) tiene el significado del asunto al que se intenta llegar; remite al meollo de la cuestión que se busca dilucidar. "Esa cosa (Sache) es siempre la «cosa debatida» (Streitsache), la "cuestión de fondo» (die "sachliche Sache»), como quien dice" (2003: 139). En el caso concreto de Gadamer las cosas mismas son los textos significativos que se intentan comprender. Pero el significado no es algo que se revele de manera inmediata y ordinaria. A menudo acallamos el decir de la obra al imponerle nuestras pre-concepciones. Por este motivo, se torna necesario identificar ésta últimas con el propósito de someterlas a revisión crítica: "es importante que el intérprete no se dirija hacia los textos directamente, desde las opiniones previas que le subyacen, sino que examine tales opiniones en cuanto a su legitimación, esto es, en cuanto a su origen y validez" (Gadamer, 2001: 334).

Este señalamiento acerca de la necesidad de revisar críticamente los propios prejuicios, presupone que es posible suspender su dominio, es decir, que es posible distanciarnos de ellos para así someterlos a examen. Sin embargo, surge el problema de saber cómo poner a distancia los prejuicios fundamentales que constituyen nuestro horizonte de sentido. El propio Gadamer ha enfatizado que los prejuicios no son objetos que estén a nuestra disposición y que podamos manipular a voluntad. Por lo tanto, cabe preguntar al filósofo de Heidelberg lo siguiente: ¿cómo se puede dar cumplimiento a la verdadera cuestión crítica de la hermenéutica, consistente en distinguir los prejuicios legítimos de los ilegítimos? La 
solución que ofrece es la siguiente: "Sólo la distancia en el tiempo hace posible resolver la verdadera cuestión crítica de la hermenéutica" (2001: 369; énfasis mío). La distancia en el tiempo permite diferenciar los prejuicios productivos de los improductivos, en la medida en que posibilita la eliminación gradual de fuentes de error y la aparición de nuevas formas de comprensión. Gadamer lo formula de la siguiente manera:

Junto al lado negativo del filtraje que opera la distancia en el tiempo aparece simultáneamente su aspecto positivo para la comprensión. No sólo ayuda a que vayan muriendo los prejuicios de naturaleza particular, sino que permite también que vayan apareciendo aquéllos que están en condiciones de guiar una comprensión correcta (2001: 369).

El pensamiento gadameriano subraya el rendimiento hermenéutico de la distancia temporal. El paso del tiempo atenúa el dominio que los prejuicios ejercen sobre nosotros de forma que posibilita la emergencia de modos más adecuados de comprensión. Todo el mundo sabe de la dificultad para decidir si una creación contemporánea tiene un verdadero valor artístico o no. Esta complejidad reside en que nuestros prejuicios ejercen un gran poder sobre nosotros, de modo que condicionan sobremanera nuestro modo de valorar las cosas. Por este motivo, la interpretación de una obra actual suele coincidir más con nuestras expectativas de sentido que con el contenido significativo de la obra.

Cuando nos acercamos a este tipo de creaciones lo hacemos evidentemente desde prejuicios incontrolables, desde presupuestos que tienen demasiado poder sobre nosotros como para que podamos conocerlos, y que confiere a la creación contemporánea una especie de hiperresonancia que no se corresponde con su verdadero contenido y significado (Gadamer, 2001: 367-368). 
Esta cita revela un par de cuestiones fundamentales respecto a la concepción gadameriana del prejuicio. Por un lado, subraya la dificultad de controlar nuestros presupuestos como para someterlos a un examen crítico, debido a que ellos nos determinan a tal punto que permanecen inaccesibles a la conciencia. Por otro, se plantea una percepción negativa del prejuicio, la cual no parece distar mucho de la perspectiva moderna. El prejuicio es visto como un posible obstáculo en la comprensión de las obras artísticas contemporáneas. Sin embargo, este modo de valoración se aproxima más a una postura epistemológica que a una hermenéutica. Estamos aquí ante una concepción del prejuicio que aún parece conservar altas resonancias metodológicas.

Pero más allá de lo anterior, Gadamer pasa por alto que la distancia temporal no sólo permite la gradual emergencia de modos correctos de comprensión, sino que también conlleva un efecto encubridor. El paso del tiempo, en conjunción con otros factores (como el ejercicio del poder por parte de las instituciones), también facilita la imposición y consolidación de nociones erróneas. Es notable que Gadamer no contemple esta posibilidad, dado que tanto él como su maestro Heidegger han tratado, respectivamente, con el problema de los encubrimientos. Este último, por ejemplo, ha denunciado en El ser y el tiempo el olvido en que ha caído la pregunta por el sentido del ser en la filosofía occidental, debido a que se confundió el ente con el ser del ente. Desde esta perspectiva, la distancia temporal posibilitó la fijación, durante siglos, de un modo equívoco de pensar. Gadamer, por su parte, acusa al racionalismo metodológico como el responsable de velar el acceso a la verdad que el arte, la historia y la filosofía tienen que ofrecer. Pero el racionalismo metodológico hunde sus raíces en la modernidad, de modo que se precisó del paso del tiempo para su consolidación. En ambos casos, ciertas interpretaciones terminaron por imponerse y encubrir otros modos de pensamiento potencialmente más 
adecuados. De esto se sigue que la distancia temporal no sólo permite la aparición de prejuicios productivos, sino también tiene un efecto encubridor.

Estas consideraciones sugieren que la distancia temporal no responde del todo a la exigencia implícita en la cuestión crítica. Jean Grondin resalta que en la quinta versión alemana de Verdad y método, el autor realizó una importante modificación adverbial. En lugar de afirmar que "Sólo la distancia en el tiempo..." se sostiene que "A menudo la distancia en el tiempo..." (Cf. 2003: 145). Con esta breve pero importante corrección, Gadamer admite que estaba equivocado al considerar la distancia temporal como la única forma de resolver la cuestión crítica. Para Grondin esta modificación representa un maravilloso ejemplo de un pensador que tiene una clara conciencia hermenéutica; esto es, de alguien que se encuentra dispuesto a modificar su planteamiento inicial si éste se revela inadecuado. Grondin tiene razón en reconocer y elogiar esta actitud de apertura y cambio. Sin embargo, a pesar de esta acertada rectificación, lo cierto es que ella representa una respuesta más moderada, que aún conlleva sus propias preguntas. La modificación de adverbio sugiere que puede haber otros modos de resolver la cuestión crítica, además de la distancia temporal. Sin embargo, Gadamer no ofrece pistas acerca de este asunto. De hecho, Grondin subraya que el tema del prejuicio (y con él, el de la cuestión crítica) apenas vuelve a ser mencionado en textos posteriores a Verdad y método (Cf. 2003: 145).

\section{Una tensión fundamental en Verdady método}

Es importante subrayar que la cuestión crítica no es un problema menor en la hermenéutica gadameriana. Recordemos que el dominio de los prejuicios inconscientes puede velar el significado de la obra, de modo que cancela la comprensión. En este sentido, 
la cuestión crítica, que exige revisar la validez de los prejuicios, se revela como condición necesaria del entender. Sin embargo, la instancia crítica sigue siendo formulada en términos muy próximos al racionalismo moderno, pues concibe los presupuestos como obstáculos para alcanzar la comprensión. Este criterio asume que las prejuicios son susceptibles de ser llevados al nivel de la conciencia, pues sólo cuando han sido identificados es que podemos controlarlos y determinar su legitimidad. La cuestión crítica es formulada aún desde un plano epistemológico. A continuación quiero presentar tres citas de Verdad y método que ilustran este punto:

Una comprensión llevada a cabo desde una conciencia metódica intentará siempre no llevar a término directamente sus anticipaciones sino más bien hacerlas conscientes para poder controlarlas y ganar así una comprensión correcta desde las cosas mismas. Esto es lo que Heidegger quiere decir cuando requiere que el tema científico se «asegure» en las cosas mismas mediante la elaboración de posición, previsión y anticipación.

Con ello se vuelve formulable la pregunta central de una hermenéutica que quiera ser verdaderamente histórica, su problema epistemológico clave: ¡en qué puede basarse la legitimidad de los prejuicios? ¿En qué se distinguen los prejuicios legítimos de todos los innumerables prejuicios cuya superación representa la incuestionada tarea de toda razón crítica?

En este sentido, una conciencia formada hermenéuticamente tendrá que ser hasta cierto punto también conciencia histórica, y hacer conscientes los propios prejuicios que le guían en la comprensión con el fin de que la tradición se destaque a su vez como opinión distinta y acceda así a su derecho. Es claro que el hacer patente un prejuicio implica poner en suspenso su validez (Gadamer 2001: 336, 344 y 369, respectivamente; el énfasis en todas es mío). 
En estas referencias se pone de manifiesto las tres cuestiones siguientes. Por un lado, Gadamer vincula la tarea crítica de hacerse cargo de los propios presupuestos con la exigencia fenomenológica de asegurar el tema científico partiendo de las cosas mismas. Por otro lado, concibe la tarea de distinguir los prejuicios legítimos de los ilegítimos (esto es, la cuestión crítica) como el problema epistemológico clave de la hermenéutica. Por último, formula la exigencia de hacer patentes los presupuestos que guían la comprensión para poder controlarlos y analizarlos. Este tratamiento epistemológico del prejuicio, implícito en la cuestión crítica, entra en conflicto con la rehabilitación hermenéutica del mismo. Gadamer reivindica el prejuicio al ver expresado en él la estructura fundamental de la pre-comprensión. Esto significa que, lejos de ser un obstáculo en la busca de la verdad, se constituye como condición de posibilidad de la comprensión. Los prejuicios determinan nuestra situación hermenéutica, lo cual significa que definen el posicionamiento desde el cual tiene lugar todo proyecto de interpretación. Pero si es verdad que los prejuicios condicionan y determinan nuestra horizonte hermenéutico, entonces no son susceptibles de un examen objetivo. El propio Gadamer enfatiza que el concepto de la situación "se caracteriza porque uno no se encuentra frente a ella y por lo tanto no puede tener un saber objetivo de ella" (2001: 372). Los seres humanos no estamos en condiciones de poder distanciarnos de nuestra situación para así conocerla, pues siempre estamos inmersos en ella.

Esta imposibilidad de hacer plenamente consciente el propio horizonte hermenéutico no proviene de algún "defecto de la reflexión sino que está en la esencia misma del ser histórico que somos. Ser histórico quiere decir no agotarse nunca en el saberse" (Gadamer, 2001: 372). Esta cita exhibe, una vez más, que nuestro peculiar modo de ser histórico sobrepasa, con mucho, los alcances y posibilidades de nuestra facultad reflexiva. Pero si la situación 
hermenéutica no se encuentra a nuestra total disposición, entonces los prejuicios que la constituyen tampoco pueden ser analizados en cuanto a su origen y validez. Hay diversas partes en Verdad y método en las cuales Gadamer subraya esta incapacidad de controlar y manipular los propios presupuestos.

Los prejuicios y opiniones previos que ocupan la conciencia del intérprete no están a su disposición; éste no está en condiciones de distinguir por sí mismo los prejuicios productivos que hacen posible la comprensión de aquellos otros que la obstaculizan y producen los malentendidos (2001:365).

Si es verdad que el intérprete no está en condiciones de diferenciar los prejuicios productivos de los improductivos (porque el prejuicio nos constituye), ¿cuál es entonces el sentido de introducir una instancia crítica que demanda precisamente tal distinción? Es desconcertante la exigencia de examinar críticamente los propios prejuicios, cuando a la vez se reconoce que no son susceptibles de ser traídos al nivel de la conciencia. El pensamiento gadameriano parece oscilar aquí entre una valoración hermenéutica del prejuicio y una epistemológica. La concepción hermenéutica del prejuicio ve expresado en él la estructura condicionante de la pre-comprensión; mientras que la perspectiva epistemológica lo concibe como un obstáculo que precisa de un examen crítico. Esto sugiere una tensión entre la rehabilitación hermenéutica del prejuicio y la cuestión crítica que conlleva la exigencia de determinar su origen y validez. En resumen, Gadamer presenta en su obra principal dos valoraciones del prejuicio que entran en conflicto.

Por último, no hay que pasar por alto que el prejuicio ocupa un lugar central en Verdad y método. La segunda sección del apartado 9 de esta obra se titula "Los prejuicios como condición de la comprensión”. En esta sección Gadamer expone las condiciones bajo las cuales acontece el comprender, en el mismo sentido en 
que Kant mostró las condiciones de posibilidad del conocimiento. La importancia del prejuicio se revela en su carácter determinante de la comprensión. Sin embargo, a pesar de este descubrimiento hermenéutico, el pensamiento gadameriano aún parece varado en un terreno epistemológico, al menos en cuanto a la cuestión crítica se refiere. Jean Grondin reconoce que la tensión del pensamiento gadameriano se encuentra en su tratamiento epistemológico del prejuicio. "La aporía de Gadamer reside quizás en otra parte y, hasta ahora, fue poco vista. Se esconde ya en el concepto de prejuicio, porque éste parece presuponer que un prejuicio puede convertirse siempre en un juicio" (2003: 141). En este artículo se ha intentado exponer en detalle dicha tensión no con la intención de desestimar el trabajo de un pensador de la talla de Gadamer, sino con el propósito de mostrar que un tratamiento más adecuado del comprender precisa la superación de los confines del horizonte epistemológico.

\section{Bibliografía}

Aguilar Rivero, Mariflor, 2005, Diálogo y alteridad. Trazos de la hermenéutica de Gadamer, México, UNAM, Colección Paideia.

Descartes, René, 2006, Discurso del método. Meditaciones metafísicas, Madrid, Espasa Calpe.

Dilthey, Wilhelm, 2000, Dos escritos sobre hermenéutica. Madrid, Ediciones Istmo.

Gadamer, Hans-Georg, 2001, Verdad y método, Salamanca, Ediciones Sígueme, Colección Hermeneia.

2002, Verdad y método II. Salamanca, Ediciones Sígueme, Colección Hermeneia. , 2003, Los caminos de Heidegger, Barcelona, Herder. 

nos.

Grondin, Jean, 2003, Introducción a Gadamer, Barcelona, Herder. , 2002, Introducción a la hermenéutica filosófica, Barcelona, Herder.

,2000, El problema de la conciencia histórica, Madrid, TecHeidegger, Martin, 2007, El ser y el tiempo, México, FCE. ,2006, Ser y tiempo, Madrid, Trotta.

, 2008, Ontologia: Hermenéutica de la facticidad, Madrid, Alianza.

Husserl, Edmund, 1998, Invitación a la fenomenología, Barcelona, Paidós.

Kant, Emmanuel, 1994, Filosofía de la historia, México, FCE.

Ricoeur, Paul, 2002, Del texto a la acción, ensayos hermenéuticos II, México, FCE.

Scout Ch. E., and Sallis J. (Eds.), 2000, Interrogating the Tradition. Hermeneutics and the History of Philosophy. State University of New York Press.

Recibido: 29 de junio de 2016 Aceptado: 29 de octubre de 2016 